\title{
AN ELECTROENCEPHALOGRAPHIC AND NEUROANATOMICAL ANALYSIS OF THE SEPTAL SYNDROME
}

$\mathrm{By}$

BLAIR H. TURNER

\begin{abstract}
A DISSERTATION PRESENTED TO THE GRADUATE COUNCIL OF THE UNIVERSITY OF FLORIDA

IN PARTIAL FULFILLMENT OF THE REQUIREMENTS FOR THE DEGREE OF DOCTOR OF PHILOSOPHY
\end{abstract}


Abstract of Dissertation Presented to the Graduate Council in Partial Fulfillment of the Requirements for the Degree of Doctor of Philosophy

\title{
AN ELECTROENCEPHALOGRAPHIC AND NEUROANATOMICAL ANALYSIS OF THE SEPTAL SYNDROME
}

\author{
By \\ Blair H. Turner \\ December, 1968
}

J. A. Horel, Chairman

Department of Psychology

An investigation was made of the anatomical localization of "the septal rage" syndrome and its attenuation by a thalamic lesion. Destruction of the nucleus accumbens correlated with change in eight or thirteen measures of emotionality (correlations ranged from +0.43 to -0.77$)$. The medial and lateral septal nuclei and the medial preoptic area were correlated with three of the remaining measures, and in no nucleus did amount of damage correlate with the final two measures. Lesions in the ventrobasal thalamus and zona incerta were effective (correlations -0.47 to -0.70 ) in lowering all measures of emotionality.

Electroencephalographic abnormalities were obtained from cortical dural and depth electrodes in rats following lesions of the septal area. A high amplitude $(200 \mu \mathrm{V})$ burst of $4-5 / \mathrm{sec}$. waves (sigma rhythm) was elicited upon presentation of a threatening or novel stimulus. Latency of the sigma rhythm varied from $1.8-7.5$ secs. after stimulus presentation, and was of short duration (1-2 secs.) Sigma rhythm appeared 1-2 days after surgery, and disappeared in 4-7 days. The greatest amplitude of response was recorded over posterior cortex. 
Electroencephalographic abnormalities were obtained also during sleep and found to be abnormal in that at no time was theta activity or sleep spindles observed. High voltage slow and low voltage fast components were highly intermixed, and the signal was often extremely slow. 


\section{ACKNOWLEDGMENTS}

The author would like to express his appreciation to James A. Horel, the chairman of his doctoral committee, and to J. J. Bernstein, W. W. Dawson, F. A. King, and N. W. Perry, members of the committee. Thanks are also due John Thornby for statistical consultation, and Dorothy Robinson for histological assistance. 
TABLE OF CONTENTS

Page

Acknowledgments

ii

List of Tables

iv

List of Figures

v

Chapter I - Experiment One:

Localization of the Septal

Syndrome and its Attenuation

by Thalamic Lesions 1

Introduction

Method -... 2

Results

Discussion

Summary (-..- 16

Appendix I

References Cited in Experiment One - 30

Chapter II - Experiment Two:

Electroencephalographic Correlates of the Septal Syndrome

Introduction

Method 33

Results

Discussion - 41

Summary (- 46

References Cited in Experiment Two - 54 


\section{LIST OF TABLES}

\section{Page}

Discussion of Table I

18

Table I - Regression and Multiple Correlation

Coefficients Between Damage to Nuclei

in the Septal Region and Emotionality

Ratings

Discussion of Table II

Table II - Regression and Multiple Correlation

Coefficients Between Damage to Diencephalic Structures and Emotionality

Ratings 
Experiment One

Discussion of Figure 1.

Figure 1. - Nuclear Categories Used for Statistical Analysis

Discussion of Figure 2 . 24

Figure 2. - Representative Lesions and Their Effect on Hyperirritability Which had been Previously Induced by a Forebrain Lesion

Experiment Two

Discussion of Figure 1.

Figure 1. - Electroencephalograms of Normal and Septal Animals in Different Stimulus Situations

Discussion of Figure 2.

Figure 2. - Electroencephalograms of Lesioned and Normal Rats in a Novel Environment

Discussion of Figure 3 .

Figure 3. - Sleep Records from Animals with Septal Lesions and Normal

Controls 
CHAPTER I

Experiment One

Localization of the Septal Syndrome

and its Attenuation by Thalamic Lesions

\section{INTRODUCTION}

Lesions of the septal area of the rat produce explosive attack and flight behaviors which have been termed "septal rage" or "the septal syndrome" by King. ${ }^{15}$ Efforts to localize those nuclei in the septal region which are crucial for the production of this behavior have so far been unsuccessful. 10 Experiments relating other forebrain areas to the syndrome have yielded more positive results. King and Meyer showed that bilateral lesions of the amygdala attenuate septal rage, ${ }^{16}$ while Yutzey, Meyer, and Meyer found that cortical lesions prolonged it. 35 Hilton and Zybrozyna demonstrated that the critical path of excitation was from hypothalamus to amygdala over the stria terminalis, and then back to hypothalamus via ventral amygdalofugal fibers. ${ }^{12}$ Attention also has been given to elucidation of the peripheral sensory afferents that participate in septal behavior. Flynn found that section of the sensory afferents from the mouth area attenuated attack reactions induced in cats following hypothalamic stimulation, ${ }^{8}$ and Forkner and Doty showed a decrease in pain thresholds in septal rats. 9 These findings suggest that the most effective stimuli for rage may be mediated by 
somesthetic pathways. It follows, therefore, that the ventrobasal thalamus, site of somesthetic synapse, may be of central importance to maintenance of the septal syndrome. Examination of the histological preparation from a series of rats in a pilot experiment supported this hypothesis: lesions of the ventrobasal complex of the thalamus markedly attenuated the septal syndrome, while lesions of the dorsal and ventral hippocampus, olfactory bulbs, caudate, and anterior and midline thalamic nuclei did not.

The purpose of this experiment was twofold: first, to identify the structures in, or adjacent to, the septal area which are primary contributors to the syndrome; and second, to test the hypothesis that septal behavior is mediated by the somesthetic system. To achieve this, the major thalamic station for somesthesis, the ventrobasal area, was lesioned subsequent to septal injury. Affective behavior was measured to determine whether the thalamic lesion attenuated septal rage.

METHOD

Subjects and experimental method.-- The subjects were male LongEvans hooded rats $(N=41), 90-120$ days of age. Subjects were housed in individual cages and handled by the experimenter to gentle them. They were then rated on a modified King Emotionality Scale for at least three days. 14 The following day bilateral lesions of the septal area were produced and emotionality ratings carried out for two days postoperatively; these animals constitute Group I $(N=41)$. Then thalamic lesions were produced in those animals which displayed the full amplitude of all aspects of septal rage, as measured by the emotionality scale. 
These animals constitute Group II $(\mathrm{N}=21)$. The subjects were again rated for at least three days, beginning 18 hours postoperatively. Emotionality ratings can be made quite accurately and have been found to be very reliable.

$$
15,35,17
$$

Surgical procedure.-- Subjects were administered $0.1 \mathrm{cc}$ of atropine sulfate, $0.8 \mathrm{mg} / \mathrm{ml}$, and anesthetized with intraperitioned sodium pentobarbital, $50 \mathrm{mg} / \mathrm{ml}$. Bilateral, sometimes multiple, radio-frequency lesions were produced in the septal region by stereotaxic insertion of a stainless steel electrode $0.5 \mathrm{~mm}$ in diameter, insulated with epoxy except for $0.5 \mathrm{~mm}$ at the tip. The circuit was completed by a rectal electrode. Lesions were varied in three planes in order to damage selectively the various septal nuclei. The anterior-posterior extent was $0.5 \mathrm{~mm}$ to $2.5 \mathrm{~mm}$ anterior to bregma, the dorsal-ventral extent was from $5.5 \mathrm{~mm}$ to $7.5 \mathrm{~mm}$ ventral to the outer layer of neocortex, and the lateral extent was from the margins of the midsaggittal sinus to $1.5 \mathrm{~mm}$ lateral to the sinus. Lesions were varied in size by controlling the time of the electric current. Thalamic lesions were also varied in size and location in order to damage selectively structures in and around the thalamus. A11 injury was bilateral, and in many instances two lesions were produced on each side.

Rating scale.-- Once a day the animals were removed from their cages, placed in the testing area (a table), and rated for emotionality. The animals were scored on twelve different behaviors, which could be categorized as reaction to threat, attack, and handing: (1) reaction to visual presentation of a pencil or gloved hand; (2) reaction to a tactile stimulus produced by a tap on the back; (3) resistance to 
capture; (4) resistance to handling; (5) amount and kind of vocalization during testing; (6) response to a discrete air puff delivered through a syringe to the side of the subject's body (Puff-1); (7). response to an air puff delivered over the entire dorsal surface of the body (Puff-2); (8) response to an auditory stimulus consisting of a sharp rap on the side of the cage; (9) amount of urination and defecation during testing; (10) degree of cataplexy (a sleep-like atonic state seen when septal rats are placed on their backs); (11) amount of aggressive or defensive posturing; (12) gross motor activity measured by number of squares traversed in one minute in a defined area. For the first five catagories the rat received a score from 0-5, and from 0-3 for catagories 6-11. A final category, 13, was the sum of scores received on 1-11 (see Appendix I). Histology.-- The animals were given a lethal dose of sodium pentobarbital and perfused with 10 percent saline followed by 10 percent formalin. The brains were embedded in celloidin, cut serially at $30 \mu$ through the lesion, and every second section stained with thionine. One nonlesioned animal (normal control) within the age range of the experimentals was perfused and prepared histologically. Statistical method.-- The five main components of the septal area were chosen for examination of their contribution to the septal syndrome (Group I): (1) nucleus accumbens and anterior commissure; (2) medial septal nucleus and nucleus and tract of the diagonal band; (3) lateral septal nucleus; (4) medial preoptic area; (5) preand postcommisural fornix, including nucleus triangularis septi and nucleus septalis fimbrialis. A sixth category, the sumation of 1 
through 5, represented the total area involved in Group I. Five thalamic areas which receive somesthetic information were chosen for examination of their possible role in attenuating septal rage (Group II); (1) the thalamic reticular nucleus; (2) the thalamic radiations and the internal capsule; (3) ventrobasal thalamus and medial lemniscus; (4) zona incerta and Forel's Field; (5) other thalamic nuclei, including the anterior and lateral thalamic nuclei and nucleus medialis dorsalis, parafascicularis, reuniens, and rhomboideus. A sixth category, the summation of 1 through 5, represented the total area involved in Group II. The nuclear areas are outlined in Fig. 1, A through $\mathrm{F}$.

Each section of the brain of the intact animal (normal control) was projected onto a white background through a tabletop microprojector. The bilateral area of each of the above nuclear categories was measured in arbitrary units with a planimeter as it appeared serially. These areas were summed cumulatively for their entire rostrocaudal extent to determine the volume of each structure. The percentage of a structure as represented on each section was then determined, and each section was photographed. In addition, all five components of the septal area were summed for a total volume of the tissue involved, and the same was done for the areas involved in the thalamic lesion. The information derived from the normal control was used as a standard in computing the volume of the various areas destroyed in the experimental animals in the following manner. Slides from each experimental animal were projected until the section was found where the lesion first began. The rostrocaudal extent of the lesion was determined 
by comparing sections from experimental animals with photographs of the normal control. The percent of each nucleus already traversed up to that point was recorded from the normal control. Then for each slide through the lesion the intact area remaining for each nucleus was measured with a planimeter, summed through the lesion, and the intact percentage determined and added to that recorded earlier. The total percent of nucleus remaining intact after the lesion was subtracted from unity to obtain percent of nucleus destroyed. Percent destruction of each of the twelve nuclear categories made up the independent variables.

The data were analyzed by means of the step-wise multiple regression method. 22 The percent of nuclear destruction was the independent variable and the difference between preoperative and postoperative emotionality ratings was the dependent variable. Difference in the emotionality scores between the last preoperative and first postoperative ratings (Group I data) of the twelve behavioral categories was obtained for all animals. Following septal lesions, the process was repeated for animals receiving the second lesion (Group II data).

The step-wise multiple regression relates the emotionality score (the dependent variable) to a single nuclear area of lesion (the independent variable) which most affects the response. Then in the second step of the regression the next most effective independent variable in determining the dependent variable is added to the first. This results in a new correlation of effective lesion sites and emotionality behavior. The rest of the independent variables are added in order of their 
contribution to the dependent variable.

In summary, a method was employed to determine which one or two of a number of simultaneously lesioned. nuclei contributed most to particular behavioral patterns. This method involved determining what percent of each nucleus was destroyed, and correlating change in behavior with amount of destruction of a nuclear area.

\section{Control for experimenter bias.-- Individual variability in}

brain size and shape, coupled with inherent error in electrode placement, insure that the actual locus and extent of lesions $c$ an be determined only by histological analysis. This provides a degree of control for any rater bias which might occur. There were also controls for the effects of surgical trauma alone: unknown to the experimenter, no septal lesion was produced in two animals because of a faulty electrode, and no change in emotionality was detected; in several animals the lesion intended for the ventrobasal thalamus was discovered at histological examination to have been outside the intended area (Fig. 2, B), and the expected behavioral effect did not occur; in four of the 21 Group II animals a sham operation was performed in which holes were drilled in the cranium but no lesion made, and again there was no effect on postoperative behavior; finally, the experimenter arranged the data sheets so that he was unaware of each animal's previous ratings and, whenever possible, of the type of lesion sustained. These precautions were taken in order to lower variability in the data, since inaccuracy of lesion placement, errors of measurement, and differences in brain size would distribute experimental effects among the dependent variables and result in no significant 
difference between them.

\section{RESULTS}

Group I. -- The anatomico-behavioral results of the first lesion are given in Table I. All values are significant at least at the .05 leve1. Two subscales, Puff-1 and Auditory, were not affected by lesion of the various nuclear areas. Of the remaining eleven, eight were affected solely by damage to nucleus accumbens. For each of the subscales Urination/Defecation and Object Presentation, the behavior is affected by damage to any of three nuclear areas; and finally, the Activity measure is influenced by lesion of the lateral septum alone. The regression coefficients are constants by which one would multiply percent nuclear damage to predict a behavioral score. The correlations between destruction of the most relevant nucleus (e.g., accumbens) and the resulting behavior are given in column $\mathrm{R}$; they are all high, indicating that change in eight behavioral measures is highly associated with amount of injury to nucleus accumbens. Multiple correlation coefficients have no sign. However, a positive regression coefficient implies a positive correlation, while a negative regression coefficient, as in the case of the Activity measure, implies a negative correlation. Column $5 R$ shows the increase in correlation if the effect of all five nuclei are added to the effect of the first. Except for the Urination/Defecation response, the increase in correlation is small, underlining the importance of the accumbens nucleus in determining the response. An estimate of the percent variance of the response accounted for by lesion of a nuclear area can be obtained 
by squaring the correlation coefficient (R). It should also be noted that total mass of tissue destroyed, which includes that of nucleus accumbens, is always less highly correlated with the behavioral result than damage to the accumbens alone. Such a finding indicates that the behaviors resulting from the forebrain lesions studied in this experiment are less an effect of destruction of mass of tissue per se in this forebrain region than of destruction of specific nuclei. Group II.-- The results of the second lesion, intended to attenuate septal emotionality, are presented in Table II. The level of significance and meaning of the numbers is the same as in Table I. In every case, except for the Activity and Urination/Defecation measures, it is either the ventrobasal thalamus or zona incerta-Forel's Field which is most involved in the attenuation of behavior. A11 correlations (R) are high, and are increased only moderately by adding the effects of destruction of other nuclear areas (5R). In four cases the category comprising all other thalamic nuclei contributed significantly to the behavior, but it should be noted that in three of these the regression coefficient is positive, implying that lesion in these areas would increase, rather than decrease, emotionality. Illustrations of six lesions, along with pre- and postoperative emotionality ratings, are given in Fig. 2. The lesions in sections A through $C$ were ineffective in lowering emotionality. Of particular interest are sections $C$ and $D$; they are similar except for the slightly more ventral placement in $D$, but differ greatly in behavioral effect. The lesions in sections $E$ and $F$ attenuated emotionality, but differed in their medio-lateral extent. These data thus strongly 
implicate both the ventrobasal complex of the dorsal thalamus and the zona incerta-Forel's Field (ventral thalamus) in the attenuation of emotionality.

\section{DISCUSSION}

Group I.-- The advantage of the histological-statistical procedure employed in this experiment is that it yields a quantitative correlation between a behavior and an anatomical locus, and eliminates noncontributing or minimally contributing anatomical loci. Thus, it was found that a number of the behaviors associated with "septal" rage result specifically from lesion of the nucleus accumbens rather than the septal nuclei. The resulting rage behaviors were found to be attenuated by a second lesion in the ventrobasal thalamus-zona incerta area. Another advantage of this method is that it permits neurological analysis of different individual behaviors instead of treating them together as a sum of scale points. Summing all behaviors would tend to mask differences among the individual components, making it difficult to determine whether they are correlated with injury to specific anatomical structures. One of the assumptions necessary for this type of analysis is that the behavior studied results from damage to nuclear masses. Interruption of tracts can occur, however, with so little tissue damage as to be unmeasurable by this technique. Therefore, it is possible that it is injury to fibers of passage within or nearby the nuclear areas studied that may be responsible for the resulting behavior. Interpretation of the results, therefore, should take into consideration fiber tracts of passage 
within or around the area surrounding the significant nucleus. All brains were re-examined in order to confirm the statistical finding that high emotionality ratings are associated with injury to nucleus accumbens. Two animals were found that had high scores, but no gross damage to the accumbens had been observable. A study of the cells in nucleus accumbens revealed a number of chromalytic neurons in one brain, and large clusters of reactive neuroglia in the other. This evidence suggests that the nucleus accumbens of both these brains had suffered traumatic injury. The lateral width of all brains was measured in order to determine whether gross brain size correlated with amount of damage to the nucleus accumbens, thus accounting for the statistical results. The correlation was not significantly different from zero.

Group II.-- The animals used in the second part of the experiment had exhibited a maximal increase in total scale score following forebrain lesion. Their preoperative average was ten points, their postoperative average was 31 . In a number of these animals, scores fell to five subsequent to the second lesion. It was not clear, however, which of two areas which had been determined statistically-ventrobasal thalamus and zona incerta-Forel's Field--was critical, since half of the rated behaviors were correlated with one area, and half with the other (Table II). Therefore, animals were grouped into those showing the least, and those showing the most attenuation, and the site of lesion was re-examined to determine whether a difference in lesion placement could be discerned. These data (e. g., Fig. 2, C and D) show that lesions which invaded the ventral thalamus 
bilaterally were extremely effective. Lesions confined to the medial lemniscus and ventrobasal thalamus were less effective, or not effective at all (Fig. 2, B and C). Fig. 2, D and E, indicates that lesions that extend into medial and lateral ventral thalamus are equally potent. Lesions of the ventral thalamus in cat $^{1}$ and $\operatorname{man}^{2}, 25$ produce the same extreme sluggishness and loss of interest in the environment seen in the rats in the present experiment.

What structures in this area are important in attenuating rage? Several lines of evidence permit elimination of the classical somesthetic afferents. A wide variety of stimuli can elicit rage in decerebrate preparations, including Group I muscle afferents, ${ }^{21}$ afferents mediating the chemoceptive aortic reflexes, ${ }^{3}$ stimulation of the vestibular nuclei and the spinal tract of the trigeminal nerve, ${ }^{5}$ and the light touch, auditory and visual stimuli used in the present experiment. However, interruption of structures which carry somesthetic information (medial lemniscus and lateral spinothalamic tracts) superimposed upon destruction of the thalamus does not affect elicitation of sham rage. ${ }^{20}$ The fact that many stimulus modalities do elicit the response, and yet the rage continues to appear after transection of sensory afferents, suggests that they are effective through their influence on the reticular activating system (RAS). 20 This is supported by experiments showing the effectiveness of electrical stimulation in lateral and medial reticular formation of medulla and pons in eliciting sham rage in decerebrates, and sham rage attenuation by RAS blockade following thiopental sodium anesthesia. ${ }^{5}$ Rage in such animals can also be eliminated by large lesions of the medial 
and lateral reticular formation at the midcollicular level. ${ }^{20}$ These data strongly indicate rage is mediated and sustained through the RAS of the brain stem and tegmentum.

It is noteworthy that the Activity measure in both Group I and Group II was correlated with nuclei which had very little effect on the other behavioral measures. Activity differs from all the other. measures in that the animal is left alone and is not forced to respond to stimuli presented by the experimenter. Thus the distinction between spontaneous and elicited behavior may result from involvement of different anatomical structures. The reduction in activity following septal lesions replicates the results of Corman, Meyer, and Meyer.

Anatomical systems and affective behaviors.-- The search for the structures critical for rage has been long and perplexing. Early experiments indicated that decortication produced undirected ("sham") rage, ${ }^{26}$ while other studies reported placidity after decortication. The same contradictory results pertain to the amygdala, 4,28 fornix, 24,34 septum, ${ }^{6}$ cingulate cortex, ${ }^{4,24}$ and nucleus accumbens, 10 This situation can be clarified by comparing the various lesions and their behavioral results. Only individual components of the rage response, elicited with difficulty, can be observed in an animal after transection at the mesodiencephalic junction. ${ }^{4}$ A decerebrate animal with caudal hypothalamus intact, however, is hyperirritable and gives a complete but undirected rage behavior pattern. ${ }^{4}$ Animals with greatly restricted forebrain lesions, as in the present case, while still hyperirritable, direct their attack toward relevant stimuli. In 
addition, there are lesions which produce the motor patterns of rage, as in chorea and hemiballism, but none of the affect. These considerations indicate that there are structures particularly involved in integrating the motor patterns of the behavior in question, others with directing behavior toward relevant stimuli, still others with the amplitude of behavior, with affect, and so on. The form rage takes will vary depending on which of these systems remain intact and which ones are disconnected.

The rage seen in "the septal syndrome" appears to result from an inability to regulate the amplitude of behavior. Rats with destruction of the nucleus accumbens are hyperreactive to threat and handling, on the one hand, and cataplectic, and hyporeactive in an exploratory situation, on the other. In addition, the abnormalities of the sleeping and waking electroencephalograms of rats lesioned in this area suggest disruption of a mechanism which regulates arousal. $^{32}$ In contrast, rats with lesions in the ventral thalamus seem impaired in their ability to achieve even a moderate level of arousal. Thus, animals from Groups I and II exhibit behaviors which could result from injury to different parts of the RAS. It appears possible that rage and hyporeactivity, or more generally amplitude of behavior, are controlled and modulated by a reticular system of fibers whose ascending $1 \mathrm{imb}$ is excitatory and extends from the RAS of the tegmentum to the forebrain, and whose descending limb feeds back on the RAS, ventral thalamus, or hypothalamus to inhibit or modulate the input. A lesion in the ascending, excitatory link would produce depressed behavior, while destruction of the descending 
inhibitory part of the circuit would disinhibit or disturb the regulation of certain behaviors. This hypothesis is based on the following anatomical data, and indirectly supported by further chemo- and electrophysiological studies.

Nauta has shown that the main ascending fibers of the RAS are in Forel's tractus fasciculorum tegmenti. 23 When this diffuse bundle reaches the diencephalon it bifurcates into a main component which traverses the ventral thalamus, and a smaller component which sends collaterals to the intralaminar nuclei of the thalamus. More recently, Shute and Lewis have described specific pathways of cholinergic fibers linking the reticular formation of the midbrain with certain limbic 29

structures. Of particular interest is a ventral tegmental pathway which arises from the pars compacta of the substantia nigra and from cells in the ventral tegmental area in the anterior mesencephalon. This tract enters the zona incerta, supramammillary and lateral hypothalamic regions, and traverses the lateral preoptic area, probably via the medial forebrain bundle, to terminate in the medial septa1diagonal band region. These afferents may constitute the ascending, excitatory link of the circuit. From the medial septum the path leads to the hippocampus by way of the stria: of Lancisi, dorsal fornix, alveus, and fimbria, and then to the nucleus accumbens, either directly ${ }^{30}$ or by way of a synapse in the nucleus of the anterior 19

commissure. The principal efferents of the nucleus accumbens are to the lateral preoptic and lateral hypothalamic areas via the medial forebrain bundle, with significant collaterals to the paratenial and dorsomedial nuclei of the thalamus. ${ }^{18}$ These efferents may constitute 
the descending, inhibitory or modulatory link of the circuit. Other possible circuits, although not as convincing because of a lack of a common chemical substrate, include reticular projections to the basal ganglia by way of Forel's Field, 23 and to nucleus accumbens and orbitofrontal cortex by way of the rostral intralaminar nuclei. Feedback may come from the basal ganglia to the ventral thalamus via ansa and fasciculus lenticularis. 13

Evidence that the midbrain-1imbic reticular system described by Nauta and by Shute and Lewis involves sleep and arousal is seen in the work of Sterman, who obtains electrophysiological and behavioral sleep with electrical stimulation in the accumbens-diagonal band area, $^{31}$ and in the work of Hernandez-Peon, et al., who with cholinergic stim-
ulation produces sleep from the anterior commissural area, and directed rage from the anterior commissural, septal, medial preoptic, and accumbens areas. ${ }^{11}$ Rage is also produced by electrical stimulation of the lateral hypothalamus, ${ }^{33}$ through which both afferents and efferents of this system travel, and is produced by stimulation of the nucleus accumbens-ventral diagonal band area. Further investigation is needed, however, to clarify the anatomical and behavioral relation between the RAS and the forebrain.

\section{SUMMARY}

An investigation was made of the anatomical localization of "the septal rage" syndrome and its attenuation by a thalamic lesion. Destruction of the nucleus accumbens correlated with change in eight of thirteen measures of emotionality (correlations ranged from +0.43 to +0.77 ). The medial and lateral septal nuclei and the medial 
preoptic area were correlated with three of the remaining measures, and in no nucleus did amount of damage correlate with the final two measures. Lesions in the ventrobasal thalamus and zona incerta were effective (correlations -0.47 to -0.70 ) in lowering all measures of emotionality. 


\section{DISCUSSION OF TABLE I \\ $\underline{\text { Regression and Multiple Correlation Coefficients }}$ Between Damage to Nuclei in the Septal Region and Emotionality Ratings}

Regression coefficients are constants which predict a behavioral score when they are multiplied by percent nuclear damage. These constants are specific as to nucleus and to behavioral measure. Correlation coefficients denote the degree of relationship between damage to a particular nucleus and the resulting change in behavior. Positive values of the regression coefficients denote increased rating score with increased nuclear damage, while negative values denote a decrease in behavioral ratings with an increase in nuclear damage. Multiple correlation coefficients have no sign. However, a negative regression coefficient, for example, implies that the amount of nuclear damage and change in the behavioral score are negatively correlated. Numbers in parentheses denote the order in which the nuclei contribute to the behavior in question. Only values significant at $P<.05$ or beyond are shown. Abbreviations: Acc, nucleus accumbens; Ms, medial septal nucleus and diagonal band; Ls, lateral septal nucleus; Med Preop, medial preoptic area; Fx, fornix; $R$, correlation coefficient; $5 R$, combined correlations of the five nuclear areas and behavioral ratings; Total Tissue, total amount of tissue damage of the five nuclear areas. 


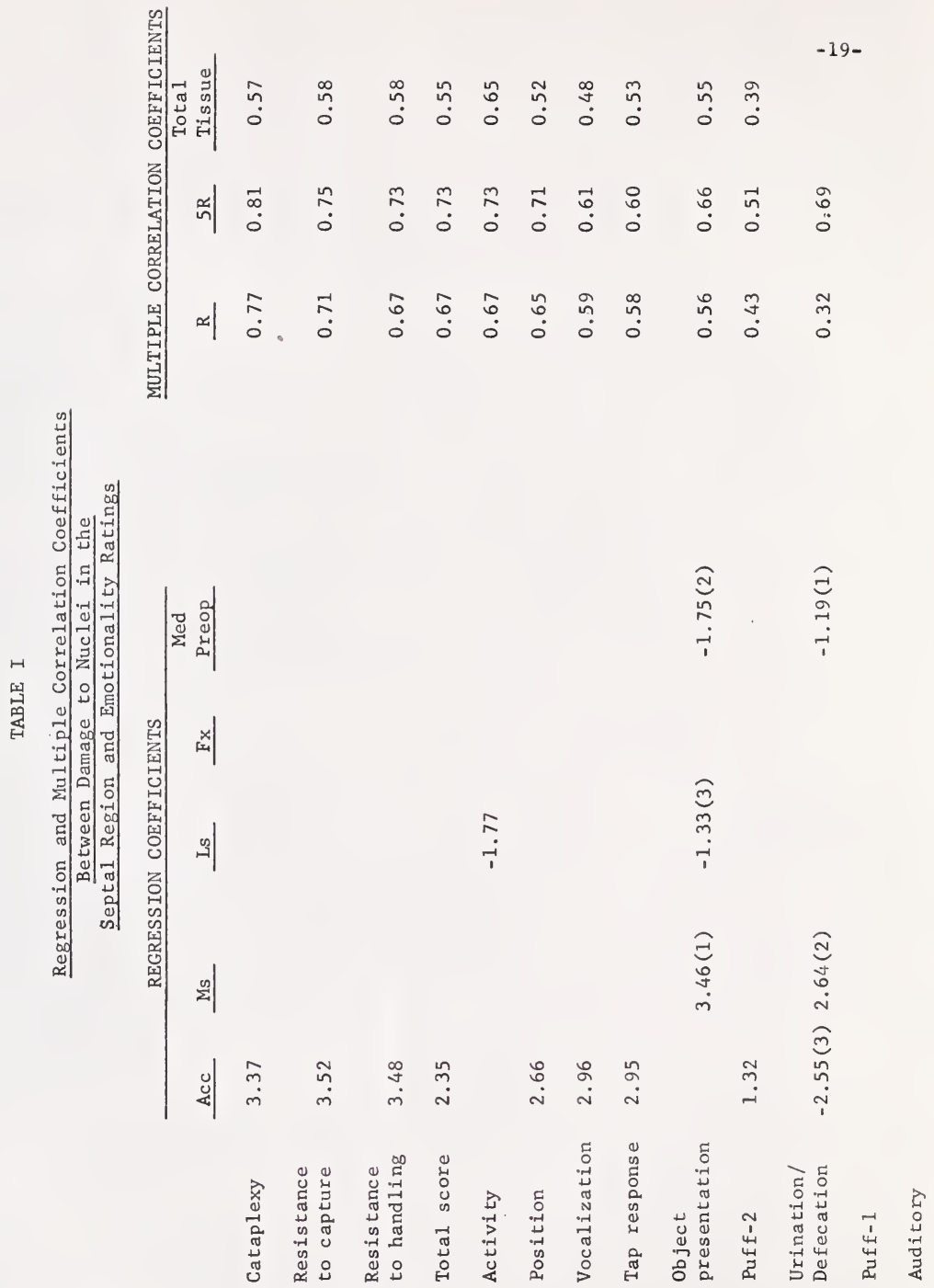




\section{DISCUSSION OF TABLE II}

Regression and Multiple Correlation Coefficients

Between Damage to Diencephalic

Structures and Emotionality Ratings

Refer to Table I for explanation of the meaning of the numbers. Only values significant at $\mathrm{P} \quad .05$ or beyond are shown. Abbreviations: Rt, thalamic reticular nucleus; Gen thal, a general category of thalamic nuclei, including the anterior, lateral, medialis dorsalis, parafascicularis, reuniens, and rhomboideus nuclei; Ventrobasal, ventrobasal complex of the dorsal thalamus; $\mathrm{Zi}$, zona incerta and Forel's Field; Ic/rti, internal capsule and thalamic radiations; Total Tissue, total amount of tissue damage of the five nuclear categories; $R$, correlation coefficient of the nucleus which most affects the behavior in question; $5 R$, combined correlations of the five nuclear areas and behavioral ratings. 


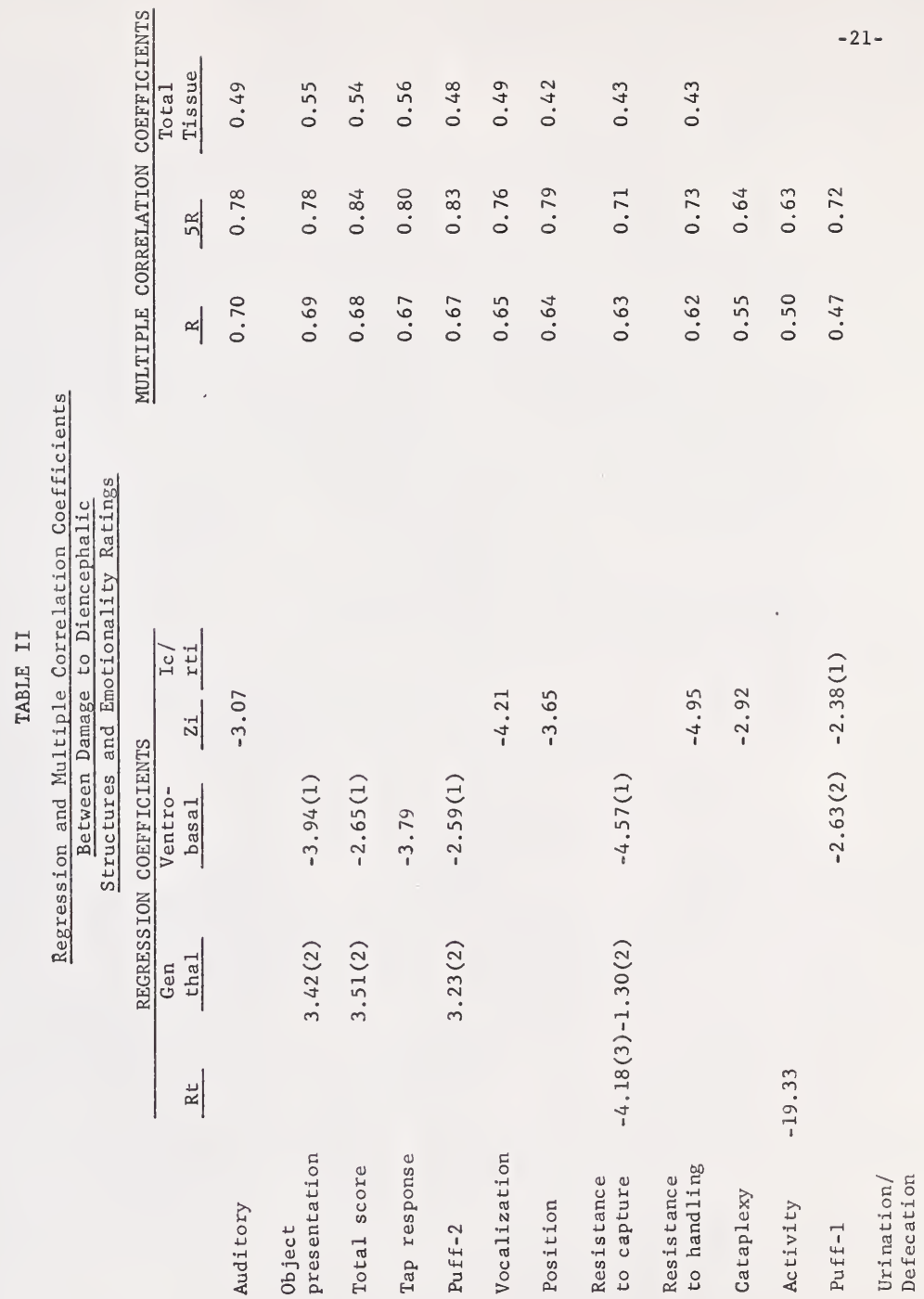




\section{DISCUSSION OF FIGURE 1. Nuclear Categories Used for Statistical Analysis}

Abbreviation: a, nucleus accumbens; $\mathrm{db} / \mathrm{ms}$, diagonal band/medial septal nucleus; 1s, lateral septal nucleus; F, fornix; rt, thalamic reticular nucleus; vb, ventrobasal complex of dorsal thalamus; zi, zona incerta/Forel's Field. The medial preoptic area is directly below the columns of the fornix. The last section, F, represents the most caudal extent of the anatomical analysis. 

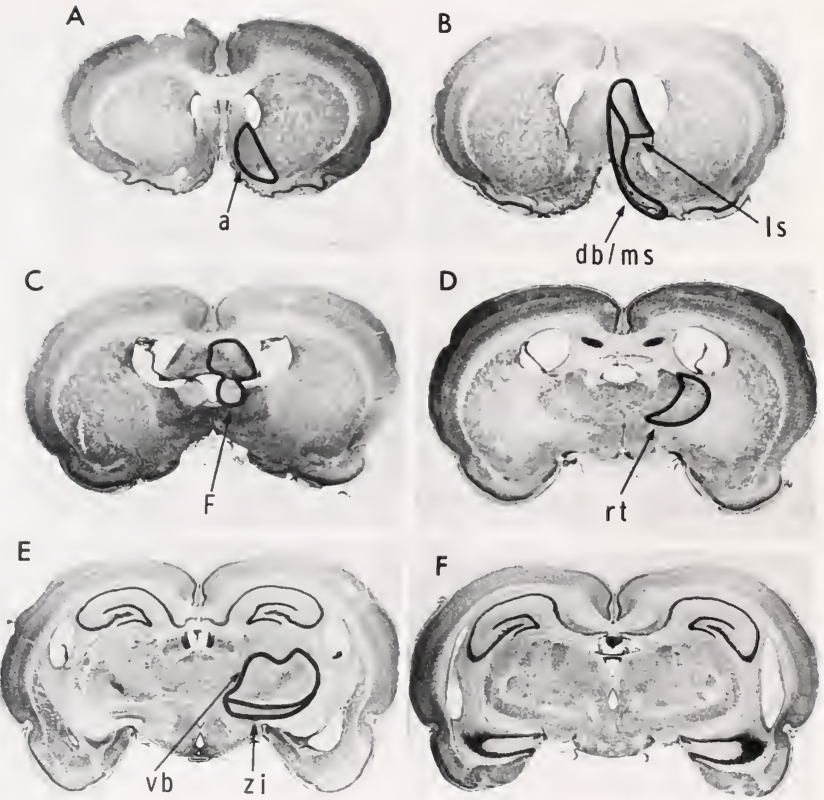

Figure 1.

Nuclear Categories Used for Statistical Analysis 


$$
\begin{gathered}
\text { DISCUSSION OF FIGURE } 2 \text {. } \\
\frac{\text { Representative Lesions and Their Effect }}{\text { On Hyperirritability Which had been Previously }} \\
\text { Induced by a Forebrain Lesion }
\end{gathered}
$$

Pre- and postoperative emotionality ratings are given for each lesion. 

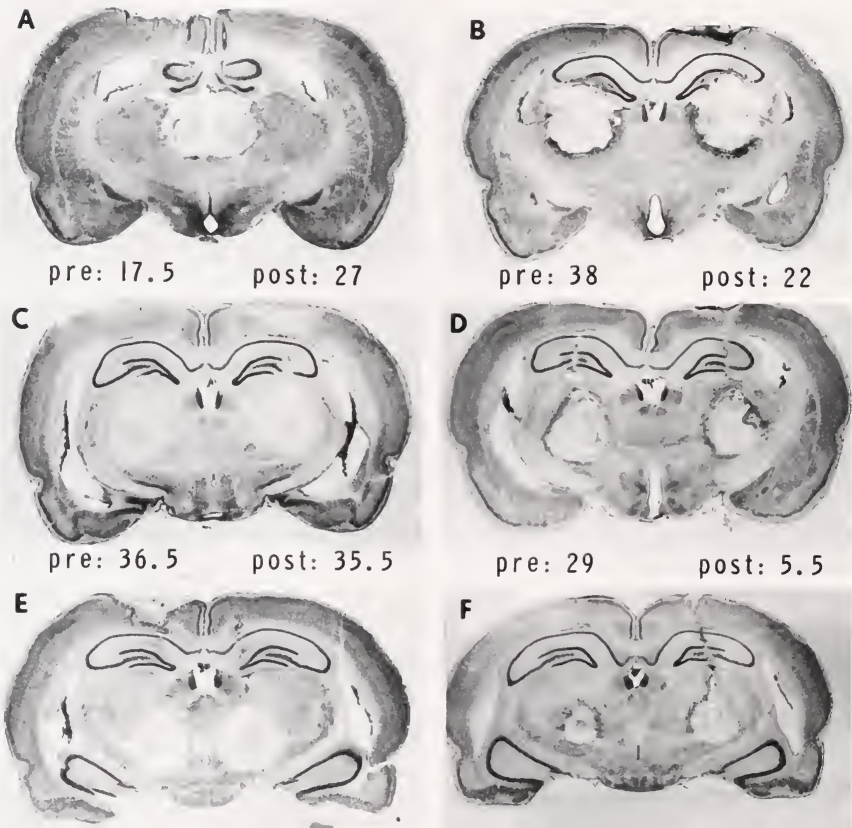

pre: 24
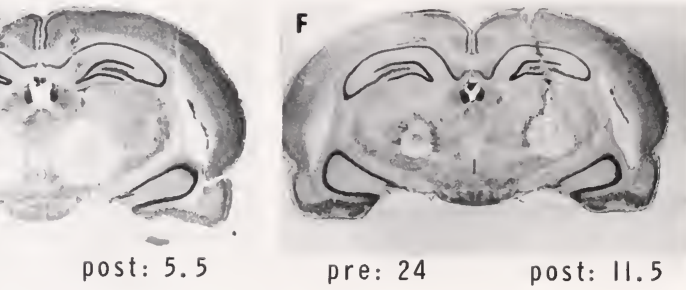

Figure 2.

Representative Lesions and Their Effect On Hyperirritability Which had been Previously Induced by a Forebrain Lesion 


\section{APPENDIX I}

\section{$\underline{\text { Rating Scale }}$}

1. Object Presentation:

Pencil is presented close to animal's snout.

0 - Rat ignores pencil; sniffs pencil; vibrissae twitch; explores.

1 - Rat alert and attentive, some body tenseness.

2 - Legs and body tense and immobile, vibrissae point forward, ears cocked.

3 - Scurries away or makes occasional mild biting attack on pencil; magnet reflex; nibbles on pencil.

4 - Intermediate.

5 - Very aggressive attack, disorganized panic; or violent flight.

2. Auditory:

A sharp rap is given to the side of the cage.

0 - No response.

1 - Orientation to the stimulus; slight startle; restless moving.

2 - Greater startle; no vocalization; jumps up on two feet.

3 - Exaggerated startle; leaps in air.

3. Puff-1:

A quick, discrete puff of air is given to the side of the animal.

0 - No response.

1 - Orientation to the stimulus; slight startle.

2 - Startle response; jumps up on two feet.

3 - Leaps in air. 
4. Puff-2:

A quick puff of air is delivered to the entire dorsal surface of the animal.

0 - No response.

1 - Orientation to the stimulus; slight startle.

2 - Startle responses; jumps up on two feet.

3 - Leaps in air.

5. Response to Tap on Back:

0 - No reaction.

0.5 - Slight muscular reflex to tap.

1 - Twitching or restlessness and slight reflex.

1.5 - Startle reflex of entire body, but not exaggerated.

2 - Twitching or scurrying away, and startle reflex and feet in air.

3 - Jumps or hops up in the air, but then settles down; exaggerated reflex.

4 - Leaps in air and runs about in fright; big hop and movement after.

5 - Leaps violently, runs off in panic, frantic rebounding in cage.

\section{Resistance to Capture:}

Glove is extended forward to animal slowly and rat is grasped. firmly but not roughly.

0 - Remains calm, does not move when approached or struggle when grasped.

1 - Remains calm when approached but runs away and tugs when grasped.

2 - Avoids on approach, struggles.

2.5 - Slips out of hand very easily.

3 - Retreats when approached, struggles vigorously when grasped.

4 - Strong attempts to escape when approached, struggles strongly and is disorganized, some biting.

5 - Leaps violently when grasped, bites frantically, very hard to catch. 
7. Resistance to Handling:

0 - Relaxes in hand, does not attempt to escape.

1 - Restless with some feeble squirming, turns over in hand.

2 - Sporadic attempts to pull out of hand, energetic squirming.

2.5 - Slips out of hand very easily.

3 - Struggles pretty continuously and quite vigorous in attempt to escape.

4 - Bites also.

5 - Frantic biting, powerful tugging, and disorganized twisting.

8. Cataplexy:

Rat is held in one hand by hindquarters, and with other is restrained in a supine position for 5-10 secs., then released.

0 - Rat sits or struggles as soon as released.

1 - Rights or struggles after release, but with a brief latency.

2 - Longer latency, head and neck tonus variable, heavy respiration.

3 - Remains supine indefinitely (over 10 secs.) and shows a marked tendency toward heavy respiration; head and neck atony.

9. Vocalization During Testing:

0 - None.

1 - Few squeaks.

2 - Frequent squeaking, a few squawks.

3 - Frequent squealing-squawking.

4 - Squealing-squawking continuous.

5 - Frantic and loud screeching continued.

10. Urination and Defecation During Testing:

0 - None.

1 - Slight urination and/or one stool.

2 - Few stools.

3 - Loose stools.

11. Posture During Testing:

0 - No definite posture or alertness; rat is on all fours.

1 - Alert and tense, on all fours.

2 - Stands on two feet.

2.5 - Also hisses or cries.

3 - Assumes aggressive or defensive posture, then attacks or retreats. 
12. Activity:

Rat is placed in a standard, confined area marked off into squares. Number of squares entered in one minute are recorded.

13. Total Score:

Total points obtained on Scales $1-11$ are summed. 


\section{REFERENCES CITED IN EXPERIMENT ONE}

1. Adey, W. R., Walter, D. 0., and Lindsley, D. F. Subthalamic lesions. Arch. Neuro1., 6(1962) 194-207.

2. Andy, 0. J., Jurko, M. F., and Sias, Fred R. Subthalamotomy in treatment of Parkinsonian tremor. J. Neurosurg., 20(1963) 860-870.

3. Baccel1i, G., Guazzi, M., Libretti, A., and Zanchetti, A. Pressoceptive and chemoceptive aortic reflexes in decorticate and in decerebrate cats. Amer. J. Physiol., 208(1965) 708-714.

4. Bard, P., and Mountcastle, V. B. Some forebfain mechanisms involved in expression of rage with special reference to suppression of angry behavior. Res. Pub1. Ass. nerv. ment. Dis., 27(1948) 362404.

5. Bizzi, E., Ma11iani, A., Apelbaum, J., and Zanchetti, A. Excitation and inhibition of sham rage behavior by lower brain stem stimulation. Arch. ital. Biol., 101(1963) 614-631.

6. Brady, J. V., and Nauta, W. J. H. Subcortical mechanisms in emotional behavior: affective changes following septal forebrain lesions in the albino rat. J. comp. physiol. Psychol., 46(1953) 339-346.

7. Corman, C. D., Meyer, P. M., and Meyer, D. R. Open-field activity and exploration in rats with septal and amygdaloid lesions. Brain Research, 5(1967) 469-476.

8. Flynn, J. P. The neural basis of aggression in cats. In D. C. Glass (ed.), Neurophysiology and Emotion, The Rockefeller University Press and Russel1 Sage Foundation, New York, 1967, p. 40.

9. Forkner, M. R., and Doty, B. Septal-lesion produced alterations in pain thresholds and avoidance conditioning. Paper presented at Midwest Psychological Association, May, 1968.

10. Harrison, O. M., and Lyon, M. The role of the septal neclei and components of the fornix in the behavior of the rat. J. comp. Neurol., 108 (1957) 121-137.

11. Hernandez-Peon, R., Chavez-Ibarra, G., Morgane, P. J., and Timo-Iaria, C. Limbic cholinergic pathways involved in sleep and emotional behavior. Exp. Neurol., 8(1963) 93-111. 
12. Hilton, S. M., and Zybrozyna, A. W. Amygdaloid region for defence reactions and $i$ ts efferent pathway to the brain stem. J. Physio1., 165 (1963) 160-173.

13. Johnson, T. N., and Clemente, C. D. An experimental study of the fiber connections between the putamen, globus pallidus, ventral thalamus, and midbrain tegmentum in cat. J. comp. Neurol., 113(1959) 83-101.

14. King, F. A. Effects of septal and amygdaloid lesions on emotional behavior and conditioned avoidance responses in the rat. J. nerv. ment. Dis., 126(1958) 57-63.

15. King, F. A. Relationship of the "septal syndrome" to genetic differences in emotionality in the rat. Psychological Reports, 5(1959) $11-17$.

16. King, F. A., and Meyer, P. M. Effects of amygdaloid lesions upon septal hyperemotionality in the rat. Science, 128(1958) 655-656.

17. Kleiner, F. B., Meyer, P. M., and Meyer, D. R. Effects of simultaneous septal and amygdaloid lesions upon emotionality and retention of a black-white discrimination. Brain Research, 5(1967) 459-468.

18. Knook, H. L: The Fibre-Connections of the Forebrain. Van Gorcum, Assen, 1965.

19. Lewis, P. R., and Shute, C. C. D. The cholinergic limbic system: projections to hippocampal formation, medial cortex, nuclei of the ascending cholinergic reticular system, and the subfornical organ and supro-optic crest. Brain, 90(1967) 521-540.

20. Malliani, A., Bizzi, E., Apelbaum, J., and Zanchetti, A. Ascending afferent mechanisms maintaining sham rage behavior in the acute thalamic cat. Arch. ital. Biol., 101(1963) 632-647.

21. Malliani, A., Carli, G., Mancia, C., and Zanchetti, A. Excitation of sham rage behavior by controlled electrical stimulation of Group I muscle afferents. Experientia, 22(1966) 315-316. 1955.

22. McNemar, Q. Psychological Statistics, John Wiley \& Sons, Inc.,

23. Nauta, W. J. H., and Kuypers, H. G. J. M. Some ascending pathways in the brain stem reticular formation. In Jasper, et al. (eds.), Reticular Formation of the Brain, Little, Brown, and Co., Boston, 1958, p. 3 . 
24. Rothfield, L., and Harman, P. J. On the relation of the hippocampal-fornix system to the control of rage responses in cats. J. comp. Neurol., 10 (1954) 265-282.

25. Sano, K. Sedative stereoencephalotomy: fornicotomy, upper mesencephalic reticulotomy, and postero-medial hypothalamotomy. In $\mathrm{T}$. Tokizane and J. P. Schade (eds.), Correlative Neurosciences, Progress in Brain Research, 21, B. Elsevier, Amsterdam, 1966, p. 350.

26. Schaltenbrand, G., and Cobb, S. Clinical and anatomical studies on two cats without neocortex. Brain, 53(1930) 449-488.

27. Scheibe1, M. E., and Scheibel, A. B. Structural organization of nonspecific thalamic nuclei and their projection toward cortex. Brain Research, 6(1967) 60-94.

28. Schreiner, L., and Kling, A. Behavioral changes following rhinencephalic injury in cat. J. Neurophysiol., 16(1953) 643-659.

29. Shute, C. C. D., and Lewis, P. R. The ascending cholinergic reticular system: neocortical, olfactory, and subcortical projections. Brain, $90(1967)$ 497-520.

30. Sprague, J. M., and Meyer, M. . An experimental study of the fornix in the rabbit. J. Anat(Lond), 84(1950) 354-368.

31. Sterman, M. B., and Clemente, C. D. Forebrain inhibitory mechanisms: sleep patterns induced by basal forebrain stimulation in the behaving cat. Exp. Neurol., 6(1962) 103-117.

32. Turner, B. H., and Sterntha1, H. Electroencepholographic correlates of the septal syndrome. (Submitted for publication.)

33. Wasman, M., and Flynn, J. P. Directed attack elicited from hypothalamus. Arch. Neurol., 6(1962) 220-227.

34. Wheatley, M. D. The hypothalamus and affective behavior in cats. Arch. Neurol. Psychiat., 52(1944) 296-316.

35. Yutzey, D. A., Meyer, P. M., and Meyer, D. R. Emotionality changes following septal neocortical ablations in rats. J. comp. physiol. Psychol., 58 (1964) 463-465. 


\section{CHAPTER II}

\section{Experiment Two}

\section{Electroencephalographic Correlates}

of the Septal Syndrome

\section{INTRODUCTION}

Rats with lesions of the septal area (septals) exhibit several seizure-like behaviors. Most notable are vicious biting attacks or frantic flight, and loud and sustained screeching when attempts are made to capture and handle lesioned animals. A peculiar hop, and a sleep-like atonic state (cataplexy) when lesioned animals are placed on their backs are also observed. In contrast to normal rats, when left alone septals are remarkably inactive and show little exploratory behavior. The explosiveness of attack or flight may be caused by irritative seizures, whereas cataplexy is similar to sleep attacks (narcolepsy). In addition, the hypoactivity is often similar to sleep. Such a syndrome might well be reflected in electroencephalographic (EEG) abnormalities. The present experiment describes some EEG correlates of these behaviors.

\section{METHOD}

Surgical procedure.-- Subjects were Long-Evans male hooded rats $(N=22)$ 90-150 days of age. The experimental animals $(N=19)$ were administered $0.1 \mathrm{cc}$ of atropine sulfate, $0.8 \mathrm{mg} / \mathrm{ml}$, and anesthetized with 
intraperitoneal sodium pentobarbital, $50 \mathrm{mg} / \mathrm{ml}$. Bilateral, sometimes multiple, radio-frequency lesions were produced in the septal region by stereotaxic insertion of a stainless-steel electrode, $0.5 \mathrm{~mm}$ diam., insulated with spox except for $0.5 \mathrm{~mm}$ at the tip. The circuit was completed by a rectal electrode. During the operation, stainlesssteel screws were inserted into the skulls of the rats in order to record the cortical EEG. In addition, in ten of these rats tefloninsulated bipolar depth electrodes were stereotaxically placed for recording from subcortical structures. Normal animals $(\mathrm{N}=3)$ were used for control recordings. Two of these had cortical dural electrodes only, and one had dural as well as depth electrodes. Controls were maintained, housed, and underwent the same surgical procedure (except for the lesion) as the experimental animals. All animals were maintained postoperatively on ampicillin trihydrate in order to control infection.

The electrode configuration for cortical recordings was chosen from those described by Dillon ${ }^{2}$ so that slow wave sleep (HVS), paradoxical sleep (PS), and the waking EEG could be easily discriminated from each other using a two-channel recording. Two of the dural electrodes were bilaterally and symmetrically inserted over posterior cortex. The other two dural electrodes were placed anteriorly, one over motor cortex and one over frontal cortex. Recordings could be obtained between the anterior and posterior cortical electrodes, or between the anterior ones and between the posterior ones. In rats which also had depth electrodes, recordings could be obtained between 
the depth electrodes, or between depth and dural electrodes. Stainless-steel wires were led from the screws used for the cortical recording to a miniature socket. The entire electrode pedestal was cemented to the screws with dental acrylic.

Behavioral and electrophysiological procedure.-- All animals were rated preoperatively for emotionality with a modification of the scale described by King. ${ }^{6}$ The animals were also rated postoperatively for as long as they continued in the experiment. Emotionality ratings were taken to measure the septal syndrome and to determine whether changes in the behaviors were related to EEG patterns.

The experiments were begun within 24-48 hours after lesion and electrode implantation. EEG recordings were obtained in two different behavioral settings. In Setting I (response to threat, attack, and handling), the rat was placed on a table and allowed to explore for one minute. Then the experimenter placed the animal in different stimulus situations: (1) visual presentation of a pencil or gloved hand, and flashing a xenon lamp or flashlight in the animal's eyes; (2) firing a popgun near the animal; (3) tapping the rat on the back, puffing air suddenly over the dorsal surface of his back, and stroking his side with a pencil; (4) catching and handing the animal; (5) holding the animal supine on his back in order to induce cataplexy. All rats were given this behavioral battery.

For seventeen animals, EEGs were recorded during sleeping and waking (Setting II). In five septals and one control, EEGs of sleeping and waking were recorded for 30 continuous hours, beginning 24 hours after surgery. After this experiment had been terminated, it 
was discovered that the sleep-wake record was abnormal and could not be evaluated by conventional criteria. In order to observe whether the EEG abnormalities resulting from the lesion were transitory, electrodes were implanted in an additional eleven animals and recordings lasting up to four hours made daily for a period of up to eight days. Behavioral observations were made during the sleep of one control and three septals in order to ascertain the presence of the behavioral indications of PS. A11 EEGs were recorded on a 12-channe1, Grass Mode1 3, electroencephalograph. Two channels were recorded from each subject.

Histology.-- At the end of the experiment, all animals were given a lethal dose of sodium pentobarbital and perfused with 10 percent saline followed by 10 percent formalin. The brains were embedded in celloidin, cut serially at $30 \mu$ through the lesion, and every second section stained with thionine. All experimental animals were found to have total or extensive damage to the lateral and medial septum, diagonal band, nucleus accumbens, and fornix. Placement of the depth electrodes was determined by microscopic examination.

\section{RESULTS}

Setting I (response to threat, attack, and handling).-- A very prominent $4-5 /$ sec burst of electrical activity (Fig. 1, A through D) was observed in 13 of 17 rats with damage to the septal area. This activity, hereafter referred to as the septal-injury rhythm (sigma), was never recorded in the three control animals, and only rarely during exploration on the table in lesioned rats. It was easily evoked, however, by a variety of applied stimuli. An object, such as a 
gloved hand, presented suddenly in front of the rat and then quickly withdrawn, was a potent stimulus in evoking the sigma rhythm (Fig. 1, B). Similarly, a flickering lamp, a flashlight beam, a tap on the back, or a stroke along the side of the body were all capable of eliciting the sigma response (Fig. 1, A through D). Stimuli were deliberately presented in such a way that the rat could not attack the stimulus source. Large movements, but not small ones, overloaded the amplifier system and an interpretable EEG could not be obtained for 5-10 seconds afterwards. Since the latencies of sigma activity were within this period, it is not possible to say whether this burst occurs during attack. Typically, the animal was quite immobile in the period between the presentation and withdrawal of the stimulus, on the one hand, and the occurrence of the sigma burst on the other. In normal implanted control rats, the battery of stimuli uniformly failed to elicit this activity.

The frequency of the sigma rhythm was $4-5 / \mathrm{sec}$ for all rats except three: in two it was recorded at $5.5 / \mathrm{sec}$, and in another it varied from $3 \cdot 5-4 \cdot 3 / \mathrm{sec}$. The burst typically had a duration between 1-2 sec. Latency to the sigma response was from $1.8-7.5 \mathrm{sec}$ after onset of the stimulus. The amplitude of the response varied from $125-250 \mu \mathrm{V}$, although in a given rat it was constant. An enlargement of the wave is given in Fig. 2, A, and a sample of the sleeping theta rhythm from a normal control in B for comparison.

Recordings were obtained from sites verified by histology. Either no sigma activity or only a low amplitude form of it was recorded from 
the caudate (Fig. 1, A through C), lateral nucleus of the thalamus (Fig. 1, A and B), pretectal area, and neocortex just above the dorsal hippocampus at the level of the rostral habenula. Therefore, these sites can probably be ruled out as sources of the sigma activity. Recordings taken from posterior cortex to any other reference showed the full amplitude of the sigma pattern. Recordings from anterior cortex to other (subcortical) points showed a greatly diminished pattern or none at all (Fig. 1, A through D).

The sigma burst could usually be elicited within 24 hours of surgery, but in some animals it did not develop until 48 hours afterwards. In most cases the rhythm was elicited only during behavioral testing (Setting I), although occasionally it occurred "spontaneous1y." Success in eliciting sigma activity varied among animals. In most cases it was obtained with almost every stimulus presentation, while in a few it was seen only once or twice a session. In all rats the frequency of the appearance of sigma bursts decreased with time, disappearing at its earliest by the fourth postoperative day. The activity remained as long as seven days in some animals, and seemed to parallel the decline of emotionality, as measured by the emotionality scale. However, there were insufficient data to demonstrate a statistical correlation between the decline in emotionality and the disappearance of the sigma bursts.

Setting I was a situation which evoked alertness and a great deal of persistent exploratory behavior in normal controls. In contrast, septals not only did not explore, but tended to remain in one place and fall asleep, as shown by the EEG. Recordings were taken 
from all animals during cataplexy. During this state the EEG could not be distinguished from the low voltage fast (LVF) activity of alert animals.

Setting II (sleeping and waking).-- A comparison of the EEG of five septals and one control demonstrated striking abnormalities in the sleeping EEG of the lesioned animals and prevented the quantitative scoring of the records for the amount and distribution of the stages of sleep. 17 This finding was replicated in a further group of eleven animals. Recordings lasting up to four hours daily were obtained from each animal for a maximum period of eight days. EEG observations are combined for both groups. All recording was begun 24 hours after surgery. EEG records were judged independently by two experimenters for each animal, each day, on seven categories. A description and the results of each category follow.

\section{(1) Waking EEG}

A comparison was made of the LVF waking EEG of normal controls and septals. Normal animals showed normal waking LVF on the first postoperative day. Three of the twelve septals showed only short spurts of LVF on the first postoperative day. Thus their records could not be considered normal. Longer periods of the usual waking pattern had returned by day three. For the most part, therefore, the septal rat was capable of showing some periods of waking EEG that were normal in amplitude, frequency, and pattern. However, a large proportion of the time in which the animal was behaviorally awake, LVF activity alternated with the HVF pattern, or the LVF pattern was slower than normal. 


\section{(2) Sleeping EEG.}

The sleep patterns of eight of twelve septals were judged abnormal with regard to normal controls in that the usual. stages of sleep could not be discerned. 17 High frequencies were superimposed upon low frequencies, there was frequent alternation of fast and slow activity, and abnormal slowing during sleep (Fig. 3, A and B). In half of these animals the normal sleep pattern had returned after four days, in the other half it remained abnormal for the eight days of testing. The wave patterns typical of the septal EEG will be discussed in the following categories.

(a) Mixed frequencies. In ten of the experimental animals rapid alternation of HVS and LVF, or their simultaneous occurrence, resulted in a blurring of the normal sleep stages and thus made conventional scoring impractical (Fig. 3, B). This was especially true for the first and second postoperative days. Although in several rats this characteristic disappeared after two or three days, in others it recurred sporadically throughout the experiment.

(b) Septal HVS. The most obvious sleep abnormality in the septal rat was the appearance of a rhythm which, in comparison to HVS in controls was: (1) slower, (2) more regular, (3) had less superimposed fast activity, and (4) had a much longer duration. Normal sleep occassionally contains similar brief periods of activity (sometimes only a few individual waves), which occur usually 
just prior to PS onset (Fig. 3, C). Septal sleep, however, may consist predominantly of this slower HVS activity. Two variations of this abnormality, recorded from the same animal at different times, are shown in the top and bottom tracings of Fig. 3, A. This rhythm was observed in eight of twelve septals. In half of the animals this rhythm disappeared in three or four days, and in the other half it continued for the eight days of the experiment. The usual amplitude was $225 \mathrm{rV}$. Normal HVS was seen in all animals, although in several it was not evident until the second or third postoperative day.

(c) Spindle bursts. Spindle bursts of $10 / \mathrm{sec}$ in frequency were almost totally absent from the sleep of septals throughout the eight-day period. In one animal they were noted only occasionally.

(d) Theta. Theta rhythm (a sign of both PS and exploratory behavior) was never observed in lesioned animals. Nevertheless, the sleep of septals sometimes shifts suddenly from HVS to LVF, as if PS had been initiated. The behavior of three septals and one control was observed during a number of such shifts, and the characteristic irregular breathing, twitching, loss of tonus, and eye closure of PS were recorded in all instances.

\section{DISCUSSION}

Setting I (response to threat, attack, and handling)..- Sigma 
bursts (Fig. 2, A) occur within or near the frequency range of theta activity. However, these EEG patterns are distinguishable. Two types of theta are seen in the normal animal: (1) sleeping theta appears to be analyzable into a smooth $7-8 / \mathrm{sec}$. wave, of variable amplitude, with what appears to be additional spikes at the peaks and troughs of this smooth wave, thus giving theta a spike-like appearance. Sleeping theta is an indication of the initiation of PS, and is always preceded by HVS sleep. Typically, 10/sec. spindlesintermix with the HVS sleep which precedes PS onset, and the initial half minute of PS also tends to have a few spindle bursts. (2) Exploratory theta, typically seen in a moving and exploring animal in a new environment, appears analyzable into a smooth $7-8 / \mathrm{sec}$. wave with a low amplitude high frequency pattern superimposed. In contrast to sleeping theta, sigma bursts are slower and have fewer and smaller spikes. Furthermore, they are not preceded by HVS sleep nor associated with spindles. In contrast to exploratory theta, sigma bursts are slower, have little superimposed fast activity, and occur in a relatively immobile and incurious animal.

The appearance of the sigma rhythm presents two paradoxes. The first is that it occurs only after presentation of a novel or threatening stimulus, yet its long latency does not suggest a primary sensory discharge, or reticular arousal resulting from the stimulus. Secondly, this activity appears related over a period of days to the gross level of hyperirritability, although in any one test session it could only be noticed (due to recording problems) during behavioral immobility. Therefore, this burst appears in the period following the 
nonspecific orienting response and before onset of a specific behavior pattern.

Several authors have examined the relationship of different behaviors with rhythmical electrical activity. Radulovacki and Adey have correlated hippocampal theta with three behavior states:

(1) immobile alertness (a variable 4-7/sec. rhythm); (2) the orienting response (5/sec.); and (3) activity during performance of a discrimination task $(6 / \mathrm{sec}))^{13}$ None of these, however, is strictly related to a defined stimulus event, and they differ only subtly from the ongoing electrical activity. Pickenhain and Klingberg show $6-9 / \mathrm{sec}$. cortical activity appearing after orientation to the conditioned stimulus in an avoidance task. ${ }^{12}$ The 6-9/sec. activity continues during the performance of the early avoidance responses, but disappears entirely with further training. Sigma bursts do not require a conditioning stimulus for their appearance, but do require an unconditioned stimulus. These authors also report 5-6/sec. photic after-discharges after presentation of a repetitive flash. An attempt to replicate these findings in this experiment was unsuccessful. Another series of experiments has defined a $4-12 / \mathrm{sec}$. pattern occurring after positive reinforcement, and a $12-20 / \mathrm{sec}$. pattern occurring after negative reinforcement. ${ }^{16}$ These electrical rhythms (4-12/sec. and 12-20/sec.) disappear following diagonal band lesion; the sigma rhythm is therefore unrelated to these activities since it is activated only after destruction of this area. Finally, sigma activity does not appear to be a seizure discharge, since no behavior signs of seizure were noticed. However, a review by Kaada of evidence 
linking seizure discharges with increased aggression does not yet permit elimination of this alternative. 5

In review, the sigma burst differs from other electrophysiological rhythms in frequency, duration, behavioral context, and occurrence of lesion. It may represent the result of nonspecific arousal or the inhibition of nonspecific arousal, reflect recruitment of an incipient behavior sequence, represent inhibition of a goal-directed response, or be a manifestation of cerebral injury, or reorganization after injury. At present, it would seem important to define the source of sigma activity, establish what stimuli and pathways are effective in driving it, determine if it is lesion-specific, define its relation to other EEG patterns, and specify further the behavior occurring during the rhythm.

Setting II. (sleeping and waking).-- A problem in recording the EEG 24 hours postoperatively is that any abnormal effects might be due to drugs administered during surgery. For example, atropine, an anticholinergic drug, has been shown to produce an HVS activity that is strikingly similar to that observed in the sleep of the present experimental animals. ${ }^{8}, 9$ This HV activity is not due to drug effect because the effect of atropine is short in duration (2-3 hours after administration). 9 Furthermore, the pattern did not occur in nonlesioned controls tested at similar postoperative periods, and the abnormal HVS was seen in some septals as long as eight days postoperatively.

The changes in this experiment in HVS, theta, and sleep spindles --major electrical signs of sleep--demonstrate the involvement of the 
septal area in the sleep cycle, and confirms in the rat some effects observed in the septal cat by Parmeggiani and Zanocco, 10 and Jouvet. 4 The former investigators observed no theta, and found a 75 percent decrease in the occurrence of PS, which normally follows the HVS stage. However, when PS did occur, the behavioral signs were present despite absence of theta. Jouvet found no evidence at all of PS in the septal cat, and the waking EEG was normal. He did not, however, notice any change in HVS sleep. Finally, Brugge discovered no change at all in the sleeping EEG of septal rats, with the exception of the disappearance of theta waves. ${ }^{1}$ A finer anatomical analysis is needed to explain this discrepancy in the HVS sleep stage with the present results.

Stimulation experiments have demonstrated limbic involvement in all of the sleep stages. Hernandez-Peon obtained both HVS and PS with drug-induced cholinergic stimulation in the areas adjacent to the anterior commissure. ${ }^{3}$ Sterman and clemente produced spindles, slow waves, and PS in freely moving cats with electrical stimulation of the ventral diagonal band and nucleus accumbens, ${ }^{15}$ an area which also has been implicated in the septal rage syndrome. 3,18

Thus the evidence obtained from several methodological approaches implicates the forebrain in the electrophysiological manifestations of sleep. A central problem concerns the nature of this participation, and its relationship to the reticular activating system (RAS). There is now increasing evidence that the sleep-wake cycle is mediated by cholinergic nerve fibers extending from the RAS of the tegmentum to the diagonal band-medial septal area, ${ }^{14}$ projecting from there to 
the hippocampus, and then to the nucleus accumbens. It may be possible that the forebrain areas of the reticular system are involved with the relative balance of HVS sleep, PS, and waking. The septal region, for example, might selectively drive, coordinate, or modulate potentials arising in other structures that relate to the production of the two patterns of sleep. For example, the medial septal nucleus is essential for the appearance of the hippocampal theta, ${ }^{11}$ and possibly for the appearance of spindles (which probably arise in the thalamic recruiting system). 8 sleep spindles were not observed in the septal animals in this experiment. The frequency mixing seen in the present experiment may reflect the destruction of such a coordinating mechanism in the septal region.

This concept of the septal region as a modulator of sleeping and waking is supported by behavioral evidence. Septal rats are hypoactive when left alone, yet hyperreactive when handled. These behavioral extremes indicate that the effect of the lesion is not due to simple elimination, inhibition, or facilitation of pre-existing behaviors, but rather is a disruption of a system regulating the amplitude of behavior. Further evidence for the involvement of the septal region in sleep and arousal (behavior amplitude) is the finding by Turner that lesions in diencephalic reticular areas abolish the hyperemotionality of rats with the septal syndrome. ${ }^{18}$ The region that attenuates the behavior is the diencephalic extension of the RAS, whose involvement in arousal is now a classical observation.

\section{SUMMARY}

EEGs were obtained from cortical dural and depth electrodes in 
rats following lesions of the septal area. A high amplitude $(200 \mu V)$ burst of $4-5 / \mathrm{sec}$. waves (sigma rhythm) was elicited upon presentation of a threatening or novel stimulus. Latency of the sigma rhythm varied from 1.8-7.5 secs. after stimulus presentation, and was of short duration (1-2 secs.). Sigma rhythm appeared 1-2 days after surgery, and disappeared in 4-7 days. The greatest amplitude of response was recorded over posterior cortex. EEGs were also taken during sleep and found to be abnormal in that at no time was theta activity or sleep spindles observed. High voltage slow and low voltage fast components were highly intermixed, and the signal was often extremely slow. 


\section{DISCUSSION OF FIGURE 1.}

\section{Electroencephalograms of Normal and Septal Animals in Different Stimulus Situations}

Record A., flickering strobe; B., tap on the back and visual presentation of a gloved hand; C., stroke to flank; D., flashlight shined in the eyes; and E., tap and air puff to a normal control. Records A through D were obtained from rats with lesions in the septal area. Sigma bursts (4-5/sec.) were elicited in all cases, but not in the normal control (E). Electrode leads are indicated to the left of each tracing. Each EEG tracing lasts 26 secs. Abbreviations: caud., caudate nucleus; AC, PC, anterior and posterior cortex; LT, lateral nucleus of the thalamus; HIPP, electrode intended for hippocampus, but histology lost; and $L, R$, left, right. 

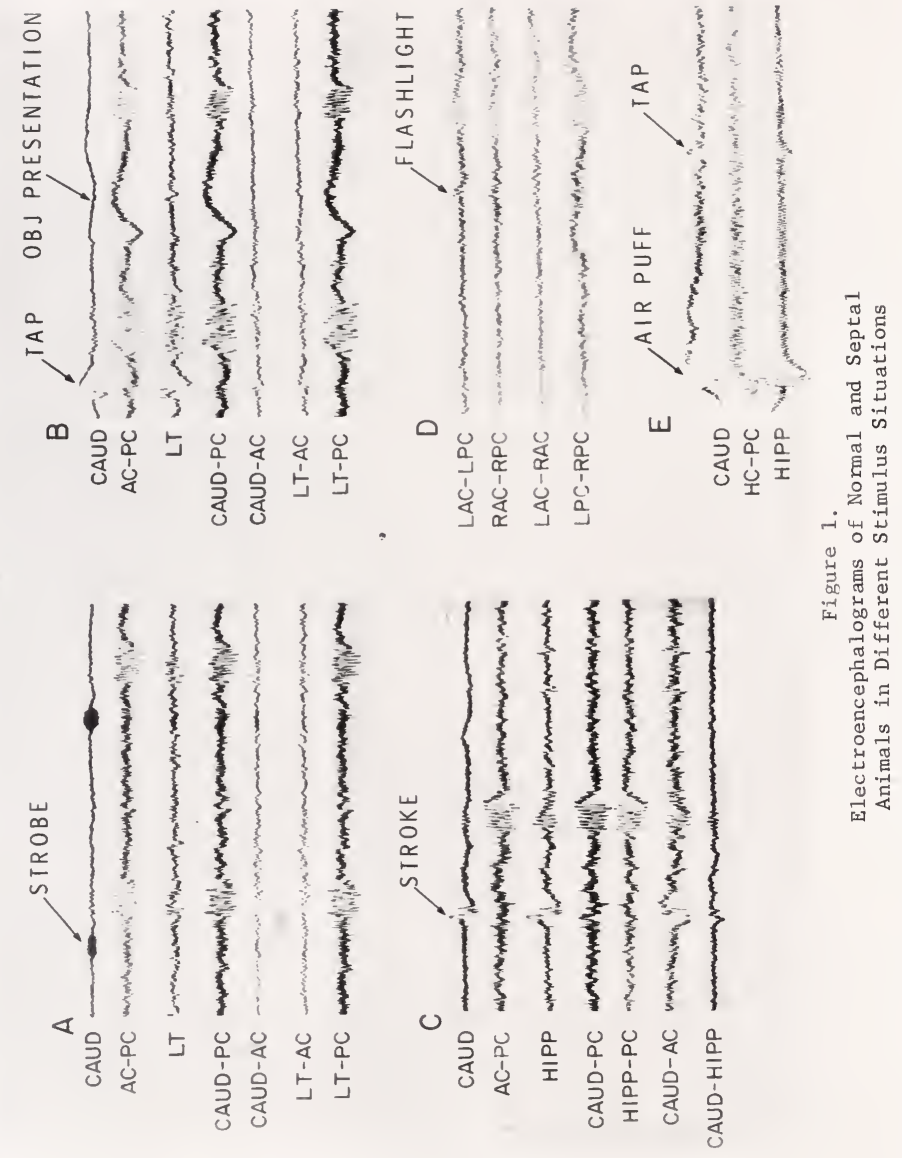


\section{DISCUSSION OF FIGURE 2.}

\section{Electroencephalograms of Lesioned and Normal}

Rats in a Novel Environment

Record A., sigma activity ( $4-5 /$ secs.) elicited by a tap on the back in a rat with septal damage; B., sample of continuous theta activity in a normal rat exploring a novel environment. 

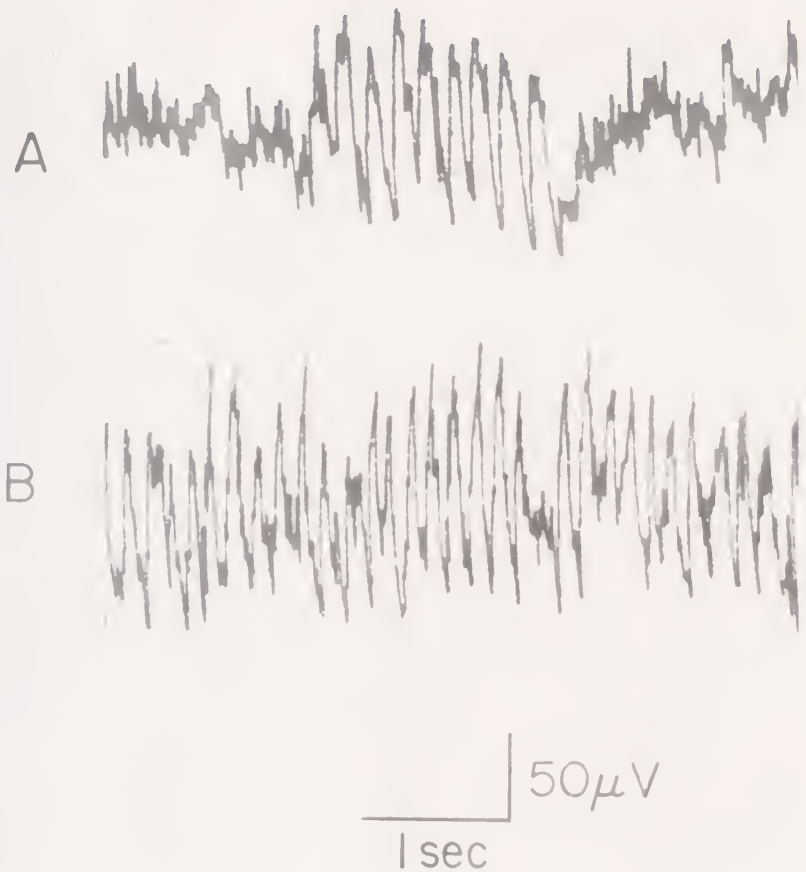

Figure 2.

Electroencephalograms of Lesioned and Normal Rats in a Novel Environment 


\section{DISCUSSION OF FIGURE 3 .}

Sleep Records from Animals with Septal Lesions and Normal Controls

Record A., top and bottom tracings are taken from the same animal at different times during sleep. The animal has a lesion in the septal area. The low voltage fast (LVF) activity in the second half of the bottom tracing indicates the rat has entered paradoxical sleep (PS) or awakened. Record B., high voltage slow (HVS) activity intermixed with LVF in a septal animal. Record C., normal animal. HVS sleep on top two channels, changing into PS sleep on bottom two channels. Top and bottom tracings are continuous. The first third of the bottom channel is HVS sleep, the second third is PS, and the last third is PS at a higher paper speed. Electrode leads are indicated to the left of each tracing. Each EEG tracing lasts 26 secs. Abbreviations: AC, PC, anterior and posterior cortex; HIPP, hippocampus . 


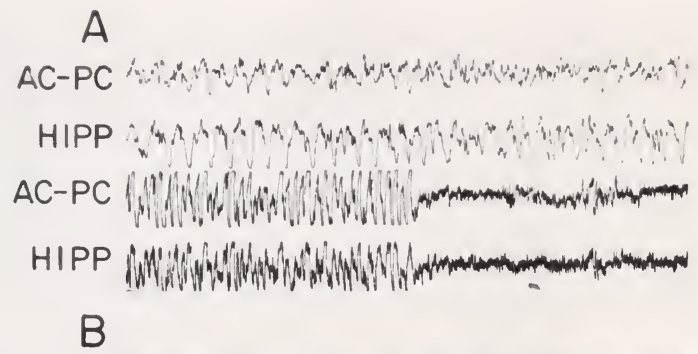

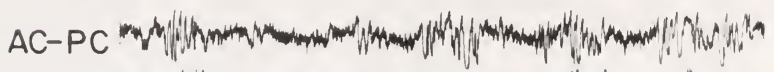

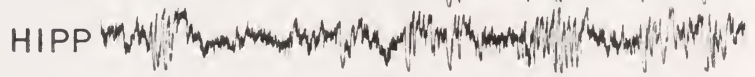

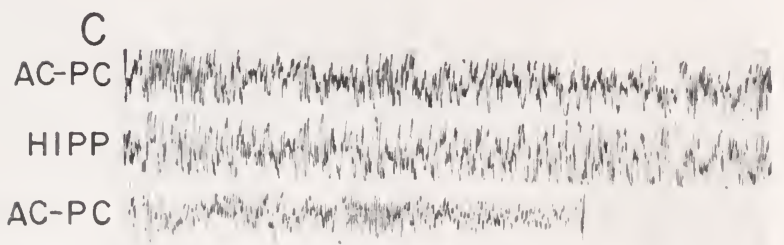

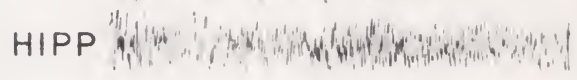

\section{Figure 3 .}

Sleep Records from Animals with Septal Lesions and Normal Controls 


\section{REFERENCES CITED IN EXPERIMENT TWO}

1. Brugge, J. F. An electrographic study of the hippocampus and neocortex in unrestrained rats following septal lesions. Electroenceph. clin. Neurophysiol., 18(1965) 36-44.

2. Dillon, R. F. The relationship between sleep and activity in the rat. Master's thesis (unpublished), University of Florida, Gainesville, Florida, 1963.

3. Hernandez-Peon, R., Chavez-Ibarra, G., Morgane, P. J., and Timo-Iaria, C. Limbic cholinergic pathways involved in sleep and emotional behavior. Exp. Neuro1., 8(1963) 93-111.

4. Jouvet, M. Recherches sur les structures nerveuses et les mecanismes responsables des differentes phases du commeil physiologique. Arch. ital. Biol., 100(1962) 125-206.

5. Kaada, B. Brain mechanisms related to aggressive behavior. In Clemente, C. D., and Lindsley, D. B. (eds.), Aggression \& Defense, University of California Press, Berkeley and Los Angeles, 1967, p. 95.

6. King, F. A. Effects of septal and amygdaloid lesions on emotional behavior and conditioned avoidance responses in the rat. J. nerv. ment. Dis., 126 (1958) 57-63.

7. Lewis, P. R., and Shute, C. C. D. The cholinergic limbic system: projections to hippocampal formation, medial cortex, nuclei of the ascending cholinergic reticular system, and the subfornical organ and supraoptic crest. Brain, 90(1967) 521-540.

8. Loeb, C., Magni, F., and Rossi, G. F. Electrophysiological analysis of the action of atropine on the central nervous system. Arch. ital. Biol., 98(1960) 293-307.

9. Longo, V. G. Effects of scopolamine and atropine on electroencephalographic and behavioral reactions due to hypothalamic stimulation. J. Pharmacol., 116 (1956) 198-208.

10. Parmeggiani, P. L., and Zanocco, G. A study on the bioelectrical rhythms of cortical and subcortical structures during activated sleep. Arch. ital. Biol., 101(1963) 385-412. 
11. Petsche, H., Stumpf, Ch., and Gogolak, G. The significance of the rabbits' septum as a relay station between the midbrain and the hippocampus. I. The control of hippocampus arousal activity by the septum cells. Eletroenceph. clin. Neurophysiol., 14(1962) 202-211.

12. Pickenhain, L., and Klingberg, F. Behavioural and electrophysiological changes during avoidance conditioning to light flashes in the rat. Electroenceph. clin. Neurophysiol., 18(1965) 464-476.

13. Radulovacki, M., and Adey, W. R. The hippocampus and the orienting reflex. Exp. Neuro1., 12(1965) 68-83.

14. Shute, C. C. D., and Lewis, P. R. The ascending cholinergic reticular system: neocortical, olfactory, and subcortical projections. Brain, 90(1967) 497-520.

15. Sterman, M. B., and Clemente, C. D. Forebrain inhibitory mechanisms: sleep patterns induced by basal forebrain stimulation in the behaving cat. Exp. Neurol., 6(1962) 103-117.

16. Sterman, M. B., and Wyrwicka, W. EEG correlates of sleep: evidence for separate forebrain substrates. Brain Research, 6(1967) $143-163$.

17. Swisher, J. Manifestations of "activated" sleep in the rat. Science, $138(1962) 1110$.

18. Turner, B. N. Localization of the septal syndrome and its attenuation by thalamic lesions. (Submit ted for publication.) 


\section{BIOGRAPHICAL SKETCH}

Mr. Turner was born January 25, 1938, in Evanston, I1linois. He attended high school and grammar school there. He graduated from Amherst College in 1960 with a Bachelor of Arts degree in American Studies and Classics. Upon graduation he then entered the U. S. Army and served for three years as a linguist in Romanian. Mr. Turner received his Master of Arts from the University of Florida in 1966 in Psychology and his Doctor of Philosophy in Physiological Psychology in 1968 . 
This dissertation was prepared under the direction of the chairman of the candidate's supervisory committee and has been approved by all members of that committee. It was submitted to the Dean $0 \hat{\varepsilon}$ the College of Arts and Sciences and to the Graduate Council, and was approved as partial fulfillment of the requirements of the degree of Doctor of Philosophy.

December, 1968

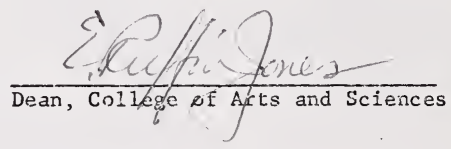

Dean, Graduate School

Supervisory Committee:

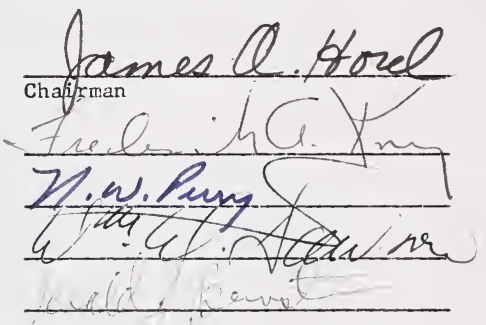

